\title{
SOBREVIVÊNCIAS, CLANDESTINIDADES, LAMPEJOS: \\ O TRABALHO VIVO DA CRIAÇÃO LITERÁRIA \\ http://dx.doi.org/10.1590/1984-0292/1322
}

João Batista de Oliveira Ferreira ${ }^{\star}$

Universidade Federal do Rio de Janeiro, Rio de Janeiro, RJ, Brasil

\section{RESUMO}

O artigo tem como objetivo refletir sobre algumas relações entre criação literária, trabalho vivo e processos de subjetivação. $O$ trabalho vivo é caracterizado como processo de criação que implica o poder de sentir, pensar e inventar. A criação literária é analisada como referência crítica às instituições das formas alienadas de viver. São propostos os conceitos de trabalho morto, subjetivação alienada, ética viva e poética da subjetivação. Com base nestas proposições, busca-se analisar a poética da subjetivação como ação que produz e é produzida pelo trabalho vivo, e também suas ressonâncias ético-políticas nos processos de construção das formas politicamente qualificadas de viver.

Palavras-chave: criação literária; subjetivação; trabalho vivo; trabalho morto.

\section{SURVIVALS, UNDERGROUNDNESS, SPARKLES:}

\section{LIVE WORK OF LITERARY CREATION}

\begin{abstract}
The article aims to analyze some relations between literary creation, living labor and processes of subjectivity. Living labor is characterized as a creation process that involves the power to feel, think and invent. The literary creation is analyzed as a critical reference of alienated forms of institutions to live. We propose the concepts of dead labor, alienated subjectivity, lively and poetic ethics of subjectivity. Based on these propositions, we seek to examine the poetic of subjectivity as an action that produces and is produced by living labor, and also its ethical-political resonances in the process of building the politically qualified forms of living.
\end{abstract}

Keywords: literary creation; subjectivity; living labor; dead labor.

\footnotetext{
^Endereço para correspondência: Universidade Federal do Rio de Janeiro, Instituto de Psicologia/Departamento de Psicologia Social. Rua Pasteur, 250 - Praia Vermelha. 22290240 - Rio de Janeiro, RJ - Brasil.E-mail: ferreira.jb@gmail.com
} 
O processo de escrever é feito de erros - a maioria essenciais - de coragem e preguiça, desespero e esperança, de vegetativa atenção, de sentimento constante (não pensamento) que não conduz a nada e de repente aquilo que se pensou que era "nada" era o próprio assustador contato com a tessitura de viver (LISPECTOR, 1984, p. 710).

Afirmar a vida é um ato ético-político. Ato que se constitui em contextos e formas diversas. No contexto produtivo marcado por processos de dominação, pela reificação e o fetichismo da mercadoria, que transforma as pessoas em coisas, o fazer artístico pode ser tomado como vertente crítica das formas de subjetivação que negam a vida?

A arte e a literatura são forças de negatividade que produzem espaços de resistência e transformação do instituído e marcam a criação como poder constituinte da condição humana (HEINICH, 2008). A arte é um "espaço de resistência ao estereótipo, à estandartização. $\mathrm{O}$ artista recupera uma poética de ruptura [...] como negação da comunicação normalizada" (PIGLIA, 1999, p. 36).

Neste artigo, a criação literária é tomada como ponto de partida para pensarmos atividades não alienadas. Analisamos o trabalho de criação literária como operador crítico das situações que impossibilitam ações de resistência e transformação das lógicas de conformação subjetiva, com base na compreensão dos processos de criação como trabalho vivo, contínua reinvenção do sujeito e do mundo e afirmação ético-política da vida.

\section{Prolixidade do Real, experiênCIA do Não lugar}

O "trabalho vivo" é entendido como processo de criação, produzido na contínua tensão com os campos normativos que regulam as formas do viver. Tais campos normativos são atravessados por instâncias mais amplas de determinação do trabalho, como as relações de poder e dominação que denominamos "campo fechado das forças instituídas". Campo que articula prescrições, regras, normas, conhecimentos, linguagem, ciência; ordenado por um tempo que se pretende linear. Campo das ideologias defensivas, sentidos fechados e dispositivos de captura. A realidade deste campo, no entanto, nunca é uma ordem inteiramente fechada, pois sua trama de sentidos não contém os movimentos inesperados e caóticos do mundo. Em tensão com esse campo fechado, há um "campo aberto das forças de ruptura", agitado por resistências, movimentos de ruptura - que ganham vida nas forças desejantes, no encontro com o outro e com as coisas do mundo, nos processos de criação.

A principal força de ruptura deste campo aberto é o "real" ("ou real do trabalho"), entendido como parte da realidade que resiste ao instituído, que irrompe como intempestivo e se opõe à significação e aos instituídos (DEJOURS, 2012). O real continuamente desativa as ordenações positivas e 
autocentradas do instituído. Produz um vazio de normas, um espaço aberto, marcado pela ausência de sentido, por aquilo que não se pode pensar nem nominar - um "não lugar" e um "tempo singular".

O "trabalho vivo" é a experiência desse real, ___ "ato poiético, momento da potência e potência da criação" (ANTUNES, 2009). Como poiésis, o "trabalho vivo" implica o poder de sentir, pensar e inventar, abre horizontes e possibilidades para a existência, para múltiplos sentidos, mobilização subjetiva e coletiva, reconfiguração normativa, práticas de transformação (DEJOURS, 2012).

O "trabalho morto" é caracterizado pela subtração da capacidade inventiva das pessoas, por vivências de mortificação e de silêncio. A vida ganha a opacidade simbólica e vivencial de um "resto no silêncio" - se resgatarmos a célebre fala de Hamlet (FERREIRA, 2009). A vida deixa de ser vida. Torna-se morte em vida. Um zero, sem lado nem avesso. Quando olhamos ao redor, para o tempo que nos foi dado viver, em contraste com os exuberantes avanços tecnológicos e a excelência onipotente das ciências da gestão, as paisagens do "admirável mundo novo" do capitalismo financeiro são atravessadas por diversas naturalizações: negação do sofrimento, adoecimentos (como a depressão), banalização da injustiça social. A sociedade do espetáculo e do consumo, no entanto, demandam vigor produtivista, corpos perfeitos, entusiasmos servis, sorrisos pré-formatados.

Avesso clandestino das práticas de dominação, o real cria contínuas dissonâncias que borram, riscam, cortam, desbotam essas paisagens. O real é prolixo, não cessa de produzir desconstruções. A "prolixidade do real" (expressão de um poema de Jorge Luis Borges) produz angústias. A tentativa de lidar com essa difusão desconcertante é a busca de dar-lhe forma por meio da palavra, na interminável procura de simbolização - marcada pelo fracasso - de constituir sentidos para o que escapa ao sentido (FERREIRA, 2011).

Ao desconstruir o ideal de domínio sobre si mesmo e sobre o mundo, o inesperado expõe o fracasso dos objetos últimos do conhecimento, da ciência, das verdades definitivamente estabelecidas, da própria configuração identitária, do tempo linear. E abre espaço para novos acontecimentos, para verdades transitórias de um tempo singular, para os "processos de subjetivação" - entendidos como processos de produção de sentido, de modos vivos de pensar, sentir, agir e significar.

$\mathrm{O}$ trabalho vivo como experiência do real e processo de criação demanda uma noção de sujeito. O sujeito não é uma definição genérica para designar uma pessoa ou um sujeito psicológico. Não é uma entidade substancial, não existe a priori, nem um lugar específico da subjetividade ou conteúdo do pensamento. $\mathrm{O}$ sujeito é efeito e produtor do processo de subjetivação; é a disposição situacional de resistência ao instituído, de resistência à ausência de sentido, mas nunca inteiramente apropriado por ele. Como força que impulsiona a subjetivação e não se deixa capturar por ela (ZIZEK, 2006), o sujeito se configura sobre um fundo de insuficiência de representação do real. 
O sujeito tem origem no "corpo". A afetividade é a base da subjetividade e da constituição do sujeito. É por meio dos afetos que a experiência do "real" do mundo se manifesta para a consciência. Os afetos são vividos na dimensão irredutível de uma corporeidade singular, apreendida de modo indireto, por aproximações difusas mediadas pela palavra. Tal singularidade afetiva expõe os limites da palavra ao tentar simbolizá-la, o que caracteriza o "déficit semiótico", a insuficiência para significar a experiência do real (DEJOURS, 2012). O trabalho de produção de sentido está submetido à condição cronicamente deficitária das tentativas de significar o real. Ainda assim, a palavra, e também a criação artística e literária, fazem nascer sentidos que não existiam, são produtoras de sentidos em ato. Composição de sentidos nunca estabelecida em definitivo, que está sempre por se fazer.

\section{Criação literária e PoÉtica da SUbJETIVaÇão}

Texto quer dizer tecido; mas enquanto até aqui esse tecido foi sempre tomado por um produto, por um véu todo acabado, por detrás do qual se conserva, mais ou menos escondido, o sentido (a verdade), nós acentuamos agora, no tecido, a ideia gerativa de que texto se faz, se trabalha através de um entrelaçamento perpétuo (BARTHES, 2006, p. 74, grifo do autor).

Para compor este fragmento de tecido sobre o trabalho de criação literária, partimos da imagem de Barthes: o texto-tecido no qual o sentido se trabalha nos entrelaçamentos de uma composição sem fim. Os fios para esta composição são citações que se trabalham no processo de fiação: "o que eu trabalho e me trabalha ao mesmo tempo? O texto, a citação" (COMPAGNON, 1996, p. 44).

As primeiras citações referem-se às tentativas de nomear a literatura e a criação literária. No livro Esse ofício do verso, Jorge Luis Borges (2007, p. 27) recorre ao comentário de Santo Agostinho sobre o tempo para marcar a impossibilidade de definir a poesia: "O que é o tempo? Se não me perguntam o que é o tempo, eu sei. Se me perguntam o que é, então não sei. Sinto o mesmo em relação à poesia". É significativo que Borges tenha buscado esse pensamento. O tempo é uma dimensão primordial do real e, assim, do trabalho de criação.

O poder desconstituinte e a força de reconfiguração produzidas pelo tempo e pela poesia se voltam contra as tentativas de capturá-los na trama dos conceitos? Ou essa impossibilidade é indicativa de que "tempo e poesia", como experiências do real, escapam inevitavelmente à nomeação? Tais questões, além de não serem excludentes, nos ajudam a pensar que o tempo, como dimensão primordial da existência, também é a dimensão primordial da poesia, pois "o tempo é o núcleo do que eu creio que seja a experiência literária. Ela é um dos modos de aparição desse elemento estranho" (PAZ, 1999, p. 99).

Mas a qual tempo nos referimos? O tempo da criação artística - e de todo trabalho de criação - se contrapõe e é potencialmente transgressor da exacerbação do tempo instrumentalizado. O trabalho do artista produz novas experiências sobre a função do tempo no trabalho "justamente por não responder a uma lógica 
do capital, que em nosso tempo propõe equivalências entre tempo e dinheiro, o artista produz muitas vezes, num longo tempo silencioso, um trabalho nem sempre visível" (SOUSA, 2000, p. 216).

A expressão latina festina lente - "apressa-te lentamente", resgatada por Calvino (1990) no livro Seis propostas para o próximo milênio, ressalta a dissonância desse tempo que se faz estranho às lógicas de dominação. "Tempo outro" da experiência "singular do real". O fazer da arte - como "espaço de resistência ao estereótipo e poética de ruptura" - possibilita o "próprio assustador contato com a tessitura de viver", como vimos na epígrafe de Clarice Lispector no início deste artigo. $\mathrm{O}$ "contato com a tessitura de viver" é a experiência do contato com o próprio tempo, o que nos aproxima da noção de contemporâneo.

O poeta - o contemporâneo - deve manter o olhar fixo em seu tempo. Mas o que vê quem vê seu tempo, o sorriso demente de seu século? [...] contemporâneo é aquele que mantém o olhar fixo no seu tempo, para nele perceber não as luzes, mas o escuro. Todos os tempos são, para quem deles experimenta contemporaneidade, obscuros. Contemporâneo é, justamente, aquele que sabe ver essa obscuridade, que é capaz de escrever mergulhando a pena nas trevas do presente (AGAMBEN, 2009, p. 62).

O poeta, como contemporâneo, vive as obscuridades do seu tempo como algo que lhe diz respeito. Escreve "mergulhando a pena nas trevas do presente" - a bela imagem da escrita capaz de, com as tintas do real, compor horizontes, possibilidades, descortinar espaços abertos para a multiplicidade dos sentidos. Escrita que se faz das obscuridades que não se submetem à forma, das sombras que não cessam de interpelar o poeta, o contemporâneo.

\section{A SALVAÇÃo dA IRREMEdiáVEl TRISTEZA das COISAS}

O escritor experimenta todos os dias o fracasso, a sensação de ser um idiota, que nunca consegue dizer o que quer - essa é a parte do trabalho de um artista. [...] Isso termina por sedimentar uma ética em alguns escritores, que os ajuda a tomar boas posições a respeito do mundo (PIGLIA, 1999, p. 136).

A "ética da não significação" que aparece neste fragmento aponta a impossibilidade do conhecimento definitivo das sombras do mundo. Aponta a criação literária como experiência do fracasso do dizer, do que não podemos dizer, nem deixar de tentar dizer. Experiência prolixa e inominável do real. "Escrever é fazer-se eco do que não pode parar de falar" (BLANCHOT, 2011a, p. 18).

O real "não lugar" que tentamos habitar com frágeis construções simbólicas. A escrita é artifício para a travessia perigosa do grande sertão do real, com tantas pedras no caminho. Quem olha o olho do sertão em pedra se transforma. Não se olha assim, diretamente. Com o artifício da arte e da palavra inventamos 
caminhos no meio das pedras do sertão, criamos veredas no espaço inominável que, com prolixidade infinita, não cessa de se anunciar. A escrita carrega vestígios que dão notícias desse grande ser, tão real.

Paisagem intraduzível, margem do inexprimível, ponto invisível - tessituras que que nos ligam à ética como a vida que não se submete, que desinventa o objeto último do conhecimento. Ética como a vida que "aceita, irrevogavelmente e sem reservas, pôr-se em jogo nos seus gestos" (AGAMBEN, 2007, p. 61). Jogo das linhas de fuga dos campos fechados que reduzem a capacidade de experienciar o mundo. Colocar-se em jogo é o que resta como possibilidade de vida, quando percebemos que "é precisamente a ausência de um objeto último do conhecimento que nos salva da tristeza sem remédio das coisas" (AGAMBEN, 2012, p. 46).

A afirmação ético-política da vida ${ }^{1}$ pede que a própria vida se coloque em jogo nos seus gestos. Isso constitui uma referência para pensarmos o gesto como "o que permanece inexpresso em cada ato de expressão [...] o autor está presente no texto apenas em um gesto, que possibilita a expressão na mesma medida em que nela instala um vazio central" (AGAMBEN, 2007. p. 59). Vazio que produz aberturas nas lógicas que se autorreplicam para garantir a permanente reprodução de mais do mesmo.

Pensar o movimento de "colocar-se em jogo" é pensar o poema como situação de risco. O poema como "experiência, do latim ex-periri: uma travessia arriscada; e no alemão Er-fahrung, que contém os semas de travessia (fahren) e de perigo (Gefahr) - mas não se pode confundir com uma vivência" (GULLAR, 2007, p. 55, grifo do autor). A situação de risco é indissociável do processo de subjetivação. Por isso, entendemos necessária a distinção entre vivência e experiência.

Didi-Huberman (2011) ressalta que as análises de Walter Benjamin sobre a impossibilidade de narrar as situações sombrias da primeira metade do século XX fizeram o valor da experiência cair de cotação. Mas a destruição da experiência é mais simples do que parece. Nenhuma grande catástrofe precisa acontecer, pois "a pacífica existência cotidiana em uma grande cidade é, para este fim, perfeitamente suficiente" (AGAMBEN, 2005, p. 21).

É possível identificar o instante em que nos distanciamos da experiência? O momento em que somos capturados pelo fluxo automático das horas que escorrem no tempo sempre igual? Em que somos tomados pela discursificação da vida cotidiana, pela falação que tenta ordenar a "fragmentação e dispersão das identificações que compõem o frágil revestimento do eu na modernidade" (KEHL, 2001, p. 87)?

O processo de perda da experiência, no entanto, ainda é experiência. A experiência não é destruída, mas se deixa capturar pela opacidade cotidiana das zonas de conforto. E, desta forma, é subjetivada como "vivência". "No ato de vivenciar, os momentos passam sem que deles nos apercebamos e se perdem na superfície dos acontecimentos" (ROCHA, 2008, p. 102). Na vivência, nós passamos pela vida, em estado de sobrevivência. Na experiência, a vida passa por nós, somos atravessados por ela, nos sentimos vivos. A experiência é central nos processos de subjetivação. 
Neste sentido, são significativas as proposições de Foucault sobre a experiência como forma de "dessubjetivação para alcançar um ponto de vista que se aproxime do não vivível, de arrancar o sujeito de si mesmo, de modo que não seja mais ele mesmo"; e também sobre a experiência como transformação associada à resistência aos dispositivos de poder e aos processos de subjetivação (CASTRO, 2009, p. 161).

Com essa perspectiva, vale apostar sempre na força indestrutível da experiência. Mesmo nas situações em que há uma morte em vida, como nos lembra Alvim (2012, p. 1013), ainda há um débil sinal de vida: "Reconhecer este sinal, gesticulação mínima, imagem quase toda borrada, requer um olhar aberto, distraidamente atento, que seja não intelectualidade, mas experiência estética, atitude que aqui chamamos marginal, atitude de espera, certa lentidão".

\section{LAMPEJOS DO INESPERADO}

Não se pode, portanto, dizer que a experiência, seja qual for o momento da história, tenha sido "destruída". Ao contrário, faz-se necessário - e pouco importa a potência do reino e de sua glória, pouca importa a eficácia universal da "sociedade do espetáculo" -, afirmar que a experiência é indestrutivel, mesmo que se encontre reduzida às sobrevivências e às clandestinidades de simples lampejos na noite (DIDIHUBERMAN, 2011, p. 148, grifo do autor).

Para o autor, o "sujeito da experiência" é um "lampejo inesperado". Tal imagem nos remete a Clarice Lispector, na constante produção de lampejos que iluminam a travessia pelas sombras do real. A citação-síntese da escritora para nosso percurso é "eu trabalho com o inesperado", do livro Um sopro de vida: pulsações (LISPECTOR, 1978, p. 14). O inesperado instaura pequenos e grandes abismos à beira dos espaços abertos e vazios que a vida continuamente nos apresenta. "Se a arte tem uma função, é a de desautomatizar as consciências. Você tem que deixar espaço para irromper o inesperado" (NOLL, 1996, p. 6). É uma citação sobre o fazer da arte, que identificamos também no fazer literário.

A experiência do real, que se manifesta no inesperado, explicita rupturas do estabelecido, do saber, do prescrito, mostra o "não saber" que produz afetos e inquietações: "todo o real é inquietante. A percepção do real, operada pelos sentidos, não dá todo o real. A margem do não saber [...] é que é inquietante" (SARAMAGO, 2010, p. 207). As inquietações, as angústias, os sentimentos de fracasso, no entanto, podem ser negados, desconsiderados - e se transformar em "vivências desses afetos". O inesperado não seria, por si só, suficiente. Somente o inesperado cuja inquietação produz riscos, dissonâncias, movimentos de criação - isto é, a "experiência do inesperado" - pode levar à produção de sentido com efeitos transitórios de verdade, que caracterizam os processos de subjetivação não alienada (FERREIRA, 2011). 
A criação literária, como "experiência do inesperado", é um percurso de risco, marcado pelo espanto de estarmos vivos. Ao se valer da linguagem para a travessia sem fim "no" e "com" o real, é um "espanto transverberado" (SANT'ANNA, 2009). O "espanto", que ganha corpo na palavra, se faz na "ruptura do tecido conceitual do mundo":

O poema nasce de um fato qualquer que me tira o equilíbrio. Eu costumo dizer que é o "espanto" a que se referia Platão: o conhecimento nasce do espanto. É um pouco isso: algo que não precisa nem ser fantástico, uma coisa qualquer. [...] $\mathrm{E}$ assim que nasce: algo se rompe, o tecido conceitual do mundo, o meu tecido conceitual - cada um tem o seu -, que mantém o mundo em ordem, que define tudo; esse tecido se rompe a qualquer momento e é preciso restabelecer o tecido, essa ferida que se abre. O poema é, de certo modo, a tentativa de incluir, eu não diria no mundo conceitual, no mundo humano experiências que não estão formuladas (GULLAR, 2007, p. 109).

A “inclusão no mundo humano de experiências não formuladas" é a inclusão de outros campos de sentido e possibilidades de vida. No movimento de reinvenção dos campos normativos e do próprio sujeito, encontramos a noção de "saúde".

A ausência de um ponto definitivamente final é a marca da saúde, da continuação, da transformação. Saúde é poder continuar. A palavra chave para Deleuze é devir o devir é sempre entre. Um corpo saudável está aí, nesse entre-estados: nesse sítio não parado que é o corpo vivo (TAVARES, 2013, p. 324).

A criação literária, como saúde, é um "trabalho vivo" "do" corpo e "com" o corpo. A saúde remete às formas de escapar da alienação, ao "retorno à arena do político, abandonada em função da fragmentação dos coletivos em um mundo dominado por grandes corporações" (DEJOURS, 2012, p. 209). Busca que demanda transgressões e "subversões poiéticas" que possibilitem "situações de autonomia ética subjetiva", como indica o autor.

A constituição do "sujeito da experiência" pelo trabalho vivo e corporal da criação dá visibilidade às forças de ruptura da imagem alienante do eu. "O sujeito só é sujeito quando é capaz de experimentar em si mesmo, algo que o ultrapassa, algo que o faz nunca ser totalmente idêntico a si mesmo. Uma experiência de des-identidade capaz de nos fazer adoecer, mas também de nos curar" (SAFATLE, 2007, p. 145).

Com a perspectiva do devir - lugar vacilante no limite de um não-lugar, habitação provisória entre o instituído e o instituinte -, coloca-se em questão o "eu estável", racionalmente senhor da sua própria casa. "A literatura só começa quando nasce em nós uma terceira pessoa que nos destitui do poder de dizer 
Eu" (DELEUZE, 2011, p. 13). Nesta passagem, perde-se a caixa de certezas e estratégias com as quais se costuma formatar o mundo. Nesta passagem do eu ao sujeito se produz uma "ética viva".

O trabalho de criação produz campos abertos, múltiplos sentidos. As fissuras nos campos fechados das forças instituídas são micro espaços para a criação sempre grande da vida. Criação que pode nos salvar do adoecimento das certezas, da tristeza irremediável das coisas mortificadas por contornos definitivos. Criação como poiética de uma "ética viva", capaz de nos fazer adoecer, mas também criar efeitos de cura.

O processo de subjetivação é uma atividade eminentemente poiética. Assim, é possível pensar "a poética de subjetivação" como "construção de linhas de fuga dos clichês que povoam à exaustão o imaginário cotidiano" (TEIXEIRA, 2000, p. 97). Na apropriação deste conceito para o contexto deste artigo, propomos uma poética "da" subjetivação, buscando enfatizar a poética produtora da subjetivação que, por sua vez, potencializa a própria poética - um fluxo em permanente devir de "subversões poiéticas".

Neste fluxo, não se pode pensar a saúde como criação da existência sem pensar a "experiência do real" e seus efeitos disruptivos e emancipatórios. Não se pode pensar o adoecimento como paralisia da existência sem pensar a "vivência do real" e seus efeitos de conformidade alienantes. A partir dessas situações não dicotômicas, sobrepostas, e em permanente estado de tensão, entendemos necessário distinguir "subjetivação alienada" e "poética da subjetivação".

A "subjetivação alienada" é uma forma de produção subjetiva instrumental, capturada na lógica dos sentidos fechados, que naturaliza relações de dominação, exclui diferenças, tenta reduzir os riscos de dissolução dos campos normativos. Induz apego a formas defensivas de manutenção do instituído, a sensibilidades amortecidas e mortificadas, ao tempo linear e planificado. A "subjetivação alienada" produz e é produzida por uma "ética da conformidade" e por vivências de negação do real. Nas situações mais intensas, é a "subjetivação alienada do trabalho morto".

A "poética da subjetivação" é a experiência de afirmação do real e do trabalho vivo. Constitui e é constituída por uma "ética viva", que ganha forma a partir da subversão poiética, das rupturas no tempo serializado da vida cotidiana, da experiência singular do tempo. A "poética da subjetivação" reconfigura o "campo fechado das forças instituídas". Nas situações de autonomia ética subjetiva, é a "subjetivação do trabalho vivo" e o "trabalho vivo da subjetivação", afirmação ética e necessariamente política da vida.

\section{O PONTO AUSENTE}

Do poema nasce o poeta. Ele nasce antes de nós e adiante de nós, como nosso próprio futuro, como o inesperado que nos atormenta e nos fascina. A cada momento, nós lhe devemos a vida e, bem mais do que a vida, o que nela, desconhecido dela, mantém acordados a coragem e o silêncio: sua verdade (BLANCHOT, 2011b, p. 119, grifo do autor). 
Esta passagem de Blanchot é uma citação-síntese para essa breve composição sobre a "poética da subjetivação", a partir da experiência da criação literária. Neste percurso, foi proposta a distinção e articulação dos conceitos de "campo fechado das forças instituídas e campo aberto das forças de ruptura, trabalho morto e trabalho vivo, vivência e experiência, subjetivação alienada e poética da subjetivação" - que tem como efeito um "sujeito da experiência".

Nossa intenção foi esboçar o fazer artístico como referência crítica das construções de subjetividade alienadas. Com essa perspectiva, a poética da subjetivação é produtora e produzida pelo "trabalho vivo".

A experiência do real é também uma experiência do contemporâneo, de ruptura da linearidade instrumentalizada e naturalizada do tempo. A experiência do real é a experiência de sentir-se em contato com o tecido da vida, que mobiliza a subjetividade para o trabalho vivo da criação, pois "o verdadeiro trabalho é aquele que, de certa forma, surpreende o trabalhador, que reconfigura sua intenção primeira" (SAFATLE, 2012, p. 390).

As condições e formas da produç.de sentido são um grande campo de pesquisas, tendo em vista a diversidade dos processos de subjetivação na contemporaneidade, marcados por formas sutis e explcitas de dominação e controle. A produção artística um campo privilegiado para pensarmos linhas de fuga, ações de resistência e enfrentamento dessas situações de captura. Isto "pede ao mesmo tempo coragem - virtude política - e poesia, que é a arte de fraturar a linguagem, de quebrar as aparências, de desunir a unidade do tempo", nos lembra Didi-Huberman (2011, p. 70), inspirado no pensamento de Agamben.

Para "nos salvar da tristeza sem remédio das coisas", precisamos de ações no mundo produzidas pelas forças de ruptura da experiência do real, pelo "lampejo inesperado que nos atormenta e fascina" - que coloquem em movimento processos de criação, poéticas da subjetivação que reconfigurem instituídos e as dimensões imaginárias do eu. Práticas atravessadas pela ausência de certezas e verdades de um "objeto último do conhecimento" - por poéticas que ganham vida nos espaços que se abrem com a "ausência de um ponto definitivamente final"

\section{Notas}

${ }^{1}$ Com base em Agamben (2010), entendemos que a dimensão ética é indissociável das ações que procuram continuamente dar forma aos modos de viver próprios de um indivíduo ou de um grupo. A ética não pode ser pensada sem as ações que buscam transformar os campos normativos adversos, sem as ações que buscam dar forma aos modos de viver que possibilitam a interminável criação do sujeito e o mundo. Formas de viver politicamente qualificadas, que caracterizam a busca de afirmação ético-política da vida.

${ }^{2}$ A "ética viva" é aqui proposta para enfatizar a dimensão constituinte da experiência como ação de transformação do sujeito e do mundo; e também como referência crítica aos "discursos éticos" (especialmente no âmbito das corporações, mas também de organizações políticas e religiosas). Tais discursos tendem a ser meros dispositivos de propaganda, cujo objetivo é criar aparência de aceitação e respeito às diferenças (dependendo do contexto da organização). Na prática, é uma "ética morta", uma "ética no papel", pautada pela lógica de conservação dessas estruturas, instrumentalizada para a manutenção das práticas de conformidade e de dominação. 


\section{REFERÊNCIAS}

AGAMBEN, G. Infância e história: destruição da experiência e origem da história. Belo Horizonte: UFMG, 2005.

AGAMBEN, G. Profanações. São Paulo: Boitempo, 2007.

AGAMBEN, G. O que é o contemporâneo? e outros ensaios. Chapecó: Argos, 2009.

AGAMBEN, G. Homo Sacer: o poder soberano e a vida nua I. Belo Horizonte: UFMG, 2010.

AGAMBEN, G. Ideia de prosa. Belo Horizonte: Autêntica, 2012.

ALVIM. M. B. A clínica como poiética. Estud. pesqui. psicol. Rio de Janeiro, v. 12, n. 3, p. 1007-1023, 2012. Disponível em: <http://pepsic.bvsalud.org/scielo. php? script=sci_arttext\&pid=S1808-42812012000300018\&lng=es\&nrm=iso $>$. Acesso em: 04 abr. 2014.

ANTUNES, R. A erosão do trabalho. Tendências e debates. Folha de São Paulo. Disponível em: <http://www1.folha.uol.com.br/fsp/opiniao/fz0105200908.htm>. Acesso em: 29 mar. 2014.

BARTHES, R. O prazer do texto. São Paulo: Perspectiva, 2006.

BLANCHOT, M. O espaço literário. Rio de Janeiro: Rocco, $2011 \mathrm{a}$.

BLANCHOT, M. René Char. In: . A parte do fogo. Rio de Janeiro: Rocco, $2011 b$.

BORGES, J. L. Esse ofício do verso. São Paulo: Companhia das Letras, 2007.

CALVINO, I. Seis propostas para o próximo milênio. São Paulo: Companhia das Letras, 1990.

CASTRO, E. Vocabulário de Foucault: um percurso pelos seus temas, conceitos e autores. Belo Horizonte: Autêntica, 2009.

COMPAGNON, A. O trabalho da citação. Belo Horizonte: UFMG, 1996.

DEJOURS, C. Trabalho vivo: trabalho e emancipação. Brasília: Paralelo 15, 2012.

DELEUZE, G. Crítica e clínica. São Paulo: Editora 34, 2011. 
DIDI-HUBERMAN, G. Sobrevivência dos vaga-lumes. Belo Horizonte: UFMG, 2011.

FERREIRA, J. B. Perdi um jeito de sorrir que eu tinha: violência, assédio moral e servidão voluntária no trabalho. Rio de Janeiro: 7Letras, 2009.

FERREIRA, J. B. Do poema nasce o poeta: criação literária, trabalho e subjetivação. Rio de Janeiro: 7Letras, 2011.

GULLAR, F. Ferreira Gullar. In: BRITO, J. D. (Org.). Como escrevo?. São Paulo: Novera, 2007. v. 2, p. 109-111.

HEINICH, N. Sociologia da arte. São Paulo: Edusc, 2008.

KEHL, M. R. Minha vida daria um romance. In: BARTUCCI, G. (Org.). Psicanálise, literatura e estéticas da subjetivação. Rio de Janeiro: Imago, 2001. p. 57-89.

LISPECTOR, C. A descoberta do mundo (crônicas). Rio de Janeiro, Nova Fronteira, 1984.

LISPECTOR, C. Um sopro de vida: pulsações. Rio de Janeiro: Nova Fronteira, 1978.

NOLL, J. G. Uma sinfonia a céu aberto. [Entrevistado por Eduardo Sterzi]. Jornal Zero Hora, Porto Alegre, 1996. Segundo Caderno, p. 1-6.

PAZ, O. Octávio Paz. [Entrevistado por Bella Jozef]. Diálogos oblíquos. Rio de Janeiro: Francisco Alves, 1999. p. 97-101.

PIGLIA, R. Ricardo Piglia. [Entrevistado por Bella Jozef]. Diálogos oblíquos. Rio de Janeiro: Francisco Alves, 1999. p. 35-39.

ROCHA, Z. A experiência psicanalítica: seus desafios e vicissitudes, hoje e amanhã. Ágora (Rio J.), Rio de Janeiro, v. 11, n. 1, p. 101-116, jan./jun. 2008. Disponível em: $<$ http://www.scielo.br/scielo.php?script=sci_arttext\&pid=S151614982008000100007\&lng=en\&nrm=iso>. Acesso em: 15 abr. 2014.

SAFATLE, V. Lacan. São Paulo: Publifolha, 2007.

SAFATLE, V. Perto demais da redenção: depressão, flexibilidade e fim da ética do trabalho. In: NOVAES, A. (Org.) Mutações: elogio à preguiça. São Paulo: Sesc SP, 2012. p. 385-404. 
SANT'ANNA, A. R. Affonso Romano de Sant'Anna. [Entrevistado por Edson Cruz]. In: O que é poesia? Rio de Janeiro: Confraria do Vento, Calibán, 2009.

SARAMAGO, J. As palavras de Saramago: catálogo de reflexões pessoais, literárias e políticas. In: AGUILERA, F. G. (Sel. e Org.). Obra literária própria. São Paulo: Companhia das Letras, 2010. p. 269-324.

SOUSA, E. L. A. Trabalhos invisíveis. In: JERUSALINSKY, A. et al. (Org.). $O$ valor simbólico do trabalho e o sujeito contemporâneo. Porto Alegre: Artes e Ofícios, 2000. p. 216-219.

TAVARES, G. Atlas do copo e da imaginação: teoria, fragmentos e imagens. Lisboa: Caminho, 2013.

TEIXEIRA, F. E. Cinema e poéticas de subjetivação. In: BARTUCCI, G. (Org.). Psicanálise, cinema e estéticas de subjetivação. Rio de Janeiro: Imago, 2000. p. 71-99.

ZIZEK, S. Arriscar o impossivel: conversas com Zizek - Slavoj Zizek, Glyn Daly: São Paulo: Martins Fontes, 2006.

Recebido em: 02 de julho de 2014 Aceito em: 03 de setembro de 2014 